\begin{tabular}{|l|l|l|}
\hline Received : 18 Maret 2018 & Accepted: 29 Maret 2018 & Published : April 2018 \\
\hline
\end{tabular}

\title{
Pemantauan Jaringan Menggunakan The Dude pada CV Teknika Bangun Wacana Berbasis Mikrotik dan Web
}

\author{
Joko Setiawan ${ }^{1,}$ Ahmad Sabiq ${ }^{2 *}$, \\ ${ }^{1,2}$ Program Studi Teknik Informatika, Fakultas Teknologi Informasi, Universitas YARSI, Jakarta. \\ *ahmad.sabiq@yarsi.ac.id
}

\begin{abstract}
CV. Teknika Bangun Wacana is a company engaged in the field of CCTV is highly dependent with access to safe and reliable information. During this time, network management in CV. Teknika Bangun Discourse is still manual, bandwidth usage during rush hour sometimes still can not be controlled and can not be monitored. In this thesis built a network in C.V. Teknika Bangun Wacana Jakarta using Mikrotik as well as web-based the dude. In this system used Mikrotik routers, operating systems Windows 10 Pro. The results of the analysis are obtained are testing system The dude based Mikrotik done in two scenarios for status detection device up and down to e-mail, the limitations of bandwidth devices connected to Mikrotik and traffic bandwidth via wesite.
\end{abstract}

Keywords : the dude, network monitoring, mikrotik.

\begin{abstract}
Abstrak
CV. Teknika Bangun Wacana merupakan perusahaan yang bergerak di bidang CCTV yang sangat tergantung dengan akses informasi yang aman dan handal. Selama ini, pengelolaan jaringan di CV. Teknika Bangun Wacana masih manual, pemakaian bandwidth pada jam sibuk terkadang masih tidak dapat terkendali serta tidak dapat dipantau. Pada penelitian ini dibangun jaringan di CV. Teknika Bangun Wacana Jakarta menggunakan dude berbasis Mikrotik serta web. Pada sistem ini digunakan router Mikrotik, Sistem operasi Windows 10 Pro. Hasil dari penelitian yang didapat pada dua sekenario pengujian yang dilakukan, sistem The dude berbasis Mikrotik dapat digunakan untuk mendeteksi status perangkat up dan down ke e-mail, pembatasan bandwidth perangkat yang terhubung ke Mikrotik dan lalu-lintas bandwidth melalui web.
\end{abstract}

Kata kunci: the dude, pemantauan jaringan, mikrotik.

\section{Pendahuluan}

CV. Teknika Bangun Wacana merupakan perusahaan yang bergerak di bidang CCTV yang sangat tergantung dengan akses informasi yang aman dan handal. Selama ini, pengelolaan jaringan di CV. Teknika Bangun Wacana masih manual, pemakaian bandwidth pada jam sibuk terkadang masih tidak dapat terkendali serta tidak dapat dipantau.

Mikrotik merupakan perusahaan yang mengembangkan produk untuk perangkat jaringan. Produk Mikrotik tidak hanya tersedia dalam produk hardware, namun juga menyediakan produk software dalam bentuk sistem operasi yang dapat diinstall di PC [1]. Sistem operasi Mikrotik berbasis Linux yang diperuntukkan sebagai network router. Didesain untuk memberikan kemudahan bagi penggunanya. Administrator Mikrotik bisa dilakukan melalui Windows Application [2]. Selain itu router Mikrotik memiliki kinerja yang lebih stabil dibandingkan PC router 
berbasis Linux, baik pada kondisi sepi, sedang maupun ramai [3].

Router Mikrotik bisa digunakan pada jaringan komputer berskala kecil hingga jaringan yang kompleks [4].

Dengan menggunakan perangkat router Mikrotik, aplikasi The Dude yang dibuat oleh Mikrotik dapat digunakan untuk melakukan monitoring jaringan [5]. The Dude merupakan aplikasi yang cukup handal dalam memonitoring sistem jaringan serta mendukung notifikasi [6]. Aplikasi The Dude pada sistem Mikrotrik dapat membantu memepermudah dan mempercepat kinerja seorang administrator jaringan dalam mendeteksi permasalahan dalam jaringan komputer [7]. Pada penelitian ini dibuatkan perancangan topologi jaringan, untuk melakukan monitoring dan memberikan informasi jika terdapat masalah pada perangkat-perangkat yang terhubung ke jaringan perangkat pada kantor CV. Tenika Bangun Wacana.

\section{Metoda Penelitian}

\subsection{Perancangan Sistem}

Tahapan perancangan sistem adalah tahapan membuat perancangan topologi jaringan yang diperlukan setelah melakukan studi literatur dan membuat rumusan masalah dari latar belakang masalah yang ada, tahap berikuktnya adalah membuat rancangan sistem

\subsubsection{Perancangan Topologi Jaringan.}

Topologi yang digunakan pada $\mathrm{CV}$. Teknika Bangun Wacana sebelum penelitian dapat dilihat pada gambar 1. Setiap device pada jaringan langsung terhubung pada router ISP yang ada.

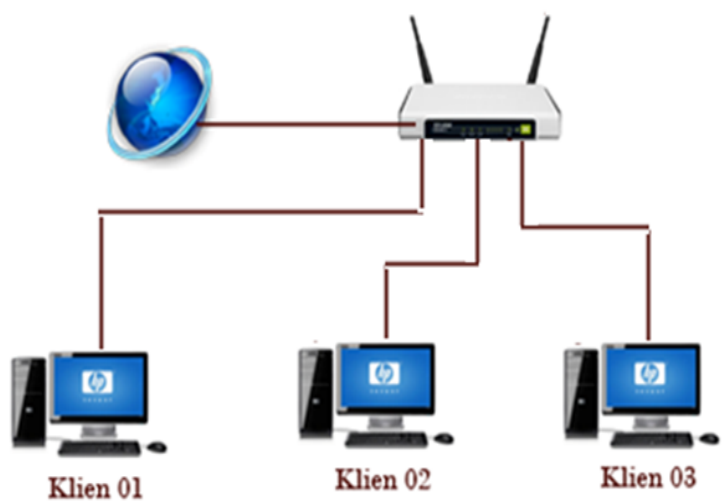

Gambar 1. Topologi di C.V Teknika Bangun Wacana

Pada penelitian ini, dirancang topologi jaringan pada CV. Teknika Bangun Wacana seperti pada gambar 2 .

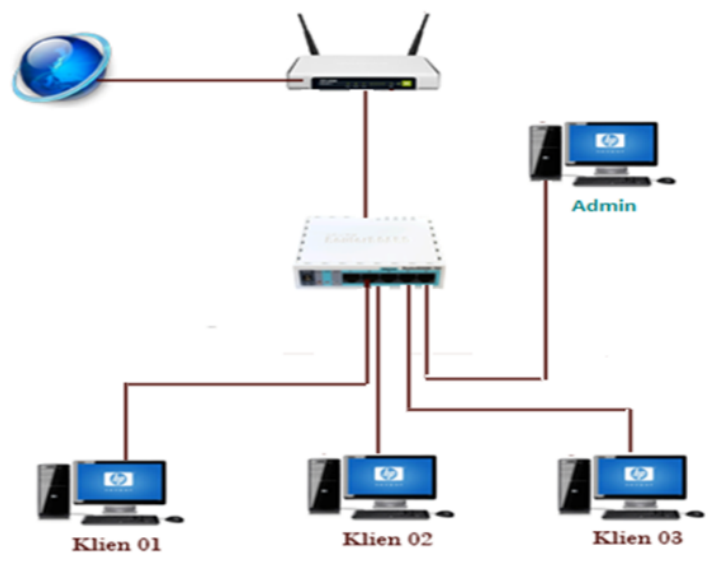

Gambar 2. Penelitian Topologi Pada C.V Teknika Bangun Wacana

Pada topologi yang dirancang untuk penelitian, terdapat 5 komponen hardware yaitu 4 PC, 1 Mikrotik dan 1 router yang terhubung dengan internet service provider (ISP). PC 1, 2, dan 3 berperan sebagai client yang terhubung ke Mikrotik. PC administrator berperan sebagai PC yang memonitor tiga PC client. Router Mikrotik berfungsi sebagai penghubung dari empat PC ke ISP dan juga berfungsi sebagai aplikasi untuk memanajemen kapasitas bandwidth.

\subsubsection{Perancangan Sistem Pemantauan Jaringan.}

Pada gambar 3 ditunjukan konfigurasi perancangan sistem pemantauan jaringan di 
The Dude ke email dengan delay 10 detik, repeat count sebanyak 1 kali dalam keadaan status down ke up, up ke down dan unstable ke down.

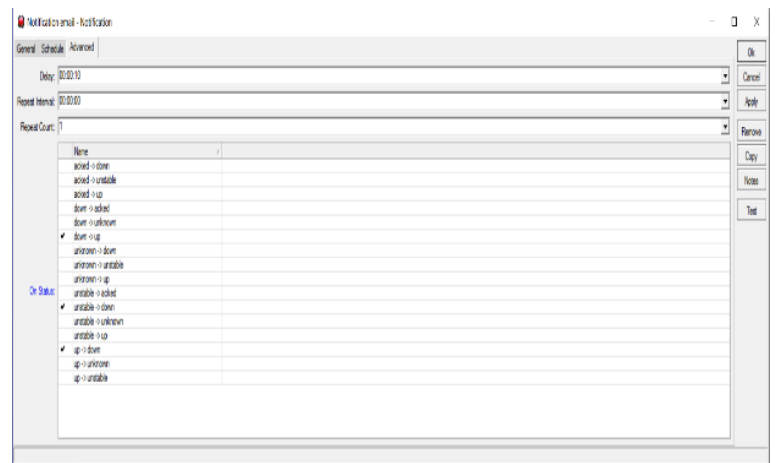

Gambar 3. Konfigurasi pematauan di The dude

\subsubsection{Perancangan pembatasan bandwidth di Mikrotik.}

Pada gambar 4 ditunjukan konfigurasi sistem pembatasan bandwidth di winbox dengan target ip 192.168.0/24, target upload $1 \mathrm{Mbps}$ dan target download $1 \mathrm{Mbps}$.

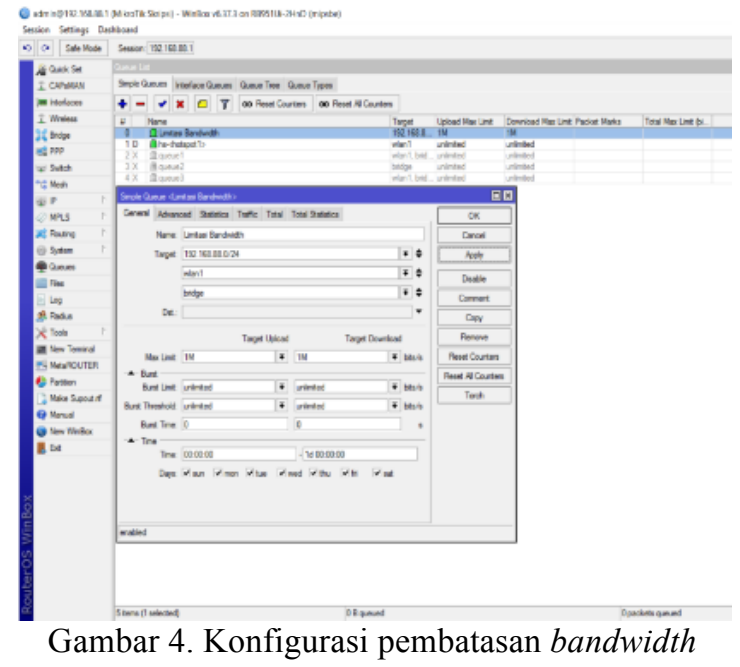

\subsection{Implementasi Sistem}

Pada tahap ini dilakukan implementasi dari sistem yang sudah dirancang sebelumnya. Perangakat router Mikrotik yang diimplementasikan pada sistem ini adalah Mikrotik Router Wireless RB951Ui-2HND.
- Install router Mikrotik serta melakukan konfigurasi ip address.

- Mengatur fitur logging pada Mikrotik

Fitur logging merupakan salah satu fitur dalam Mikrotik yang berguna dalam melakukan pencatatan berbagai aktivitas dari sistem dan informasi status router. Tujuan dari pengaturan logging ini dimaksudkan agar aktifitas yang tercatat dalam log dapat diterima oleh The Dude sebagai syslog service, rules pada system logging bertujuan untuk mencatat service pada log.

Tahap berikutnya adalah menginstall The Dude. Setelah The Dude terinstall, diisikan network yang akan dimonitoring atau scan Network atau IP yang akan dimonitoring. Discovery supaya men-scan semuanya, setelah itu klik discover untuk mulai memonitoring. Beberapa saat kemudian akan muncul tampilan network yang terhubung dengan jaringan. Client yang terhubung berwarna hijau dan yang berwarna merah adalah client yang sudah tidak terhubung.

Setelah installasi The Dude selesai, tahap berikutnya adalah memberikan informasi traffic, warna dan jumlah client melalui web secara real time kepada administrator. Pengujian dilakukan dengan melakukan pengujian jaringan berbasis Mikrotik dan web secara real time pada $\mathrm{CV}$. Teknika Bangun Wacana. Aplikasi web dibangun berbasis Xampp. Hasil web yang dibuat disimpan ke berkas C: $\mid x a m p p \backslash h t d o c s \backslash w e b-M i k r o t i k$. Hasil web yang disambung, dibuka dengan menggunakan localhost pada browser dengan aplikasi Xampp.

\section{Hasil dan Pembahasan}

\subsection{Hasil Pengujian}

Pada tahapan ini dilakukan pengujian terhadap sistem yang sudah dibangun. Pengujian dilakukan menggunakan dua skenario berbeda dan pemonitoringan bandwidth Mikrotik dengan web.

\subsubsection{Skenario pertama}

Pada gambar 5 pada peranagkat dengan alamat ip 192.168.88.250 terlihat perangkat 
tersebut terhubung ke Mikrotik dengan status up (terhubung) dan muncul notifikasi ke email saat perangkat yang terhubung ke Mikrotik terjadi up (terhubung) dengan jaringan internet dan telihat waktu device up di email.

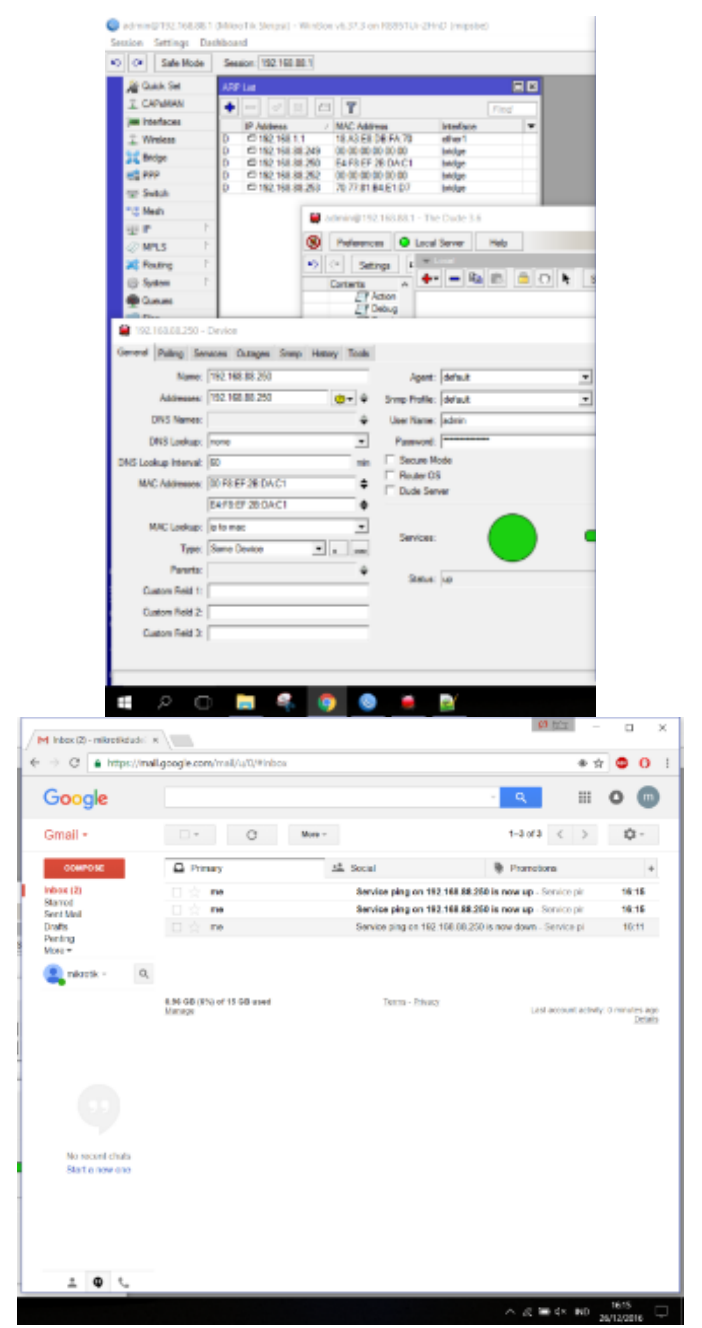

Gambar 5. Notifikasi ke e-mail saat device terhubung.

\subsubsection{Skenario kedua}

Pada gambar 6 pada perangkat dengan alamat ip 192.168.88.250 terlihat perangkat tersebut terhubung ke Mikrotik dengan status down (terputus) dan muncul notifikasi ke email saat device yang terputus ke Mikrotik terjadi down (terputus) dengan jaringan internet dan telihat waktu device down di email.

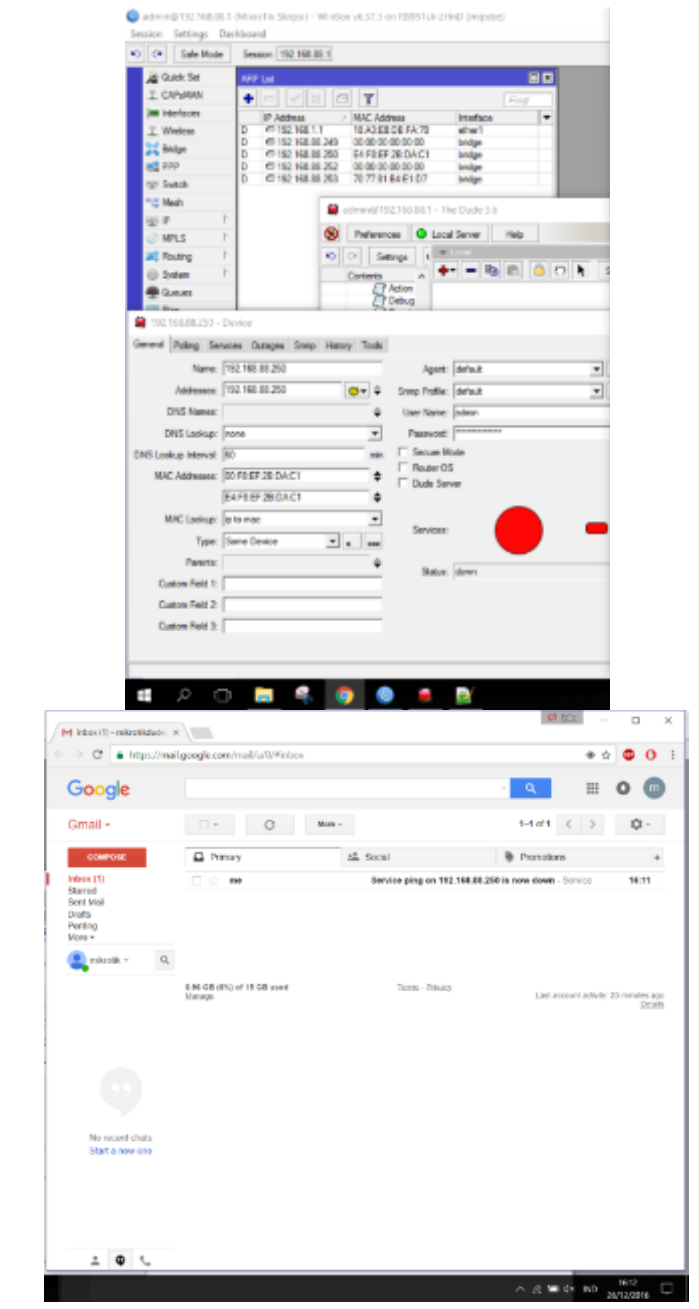

Gambar 6. Notifikasi ke e-mail saat device mati.

\subsubsection{Membatasi Bandwidth Mikrotik}

Pada gambar 7 menunjukkan grafik penggunaan bandwidth yang digunakan semua perangkat yang terhubung ke Mikrotik dengan maksimal batasan upload dan download 1 Mbps.

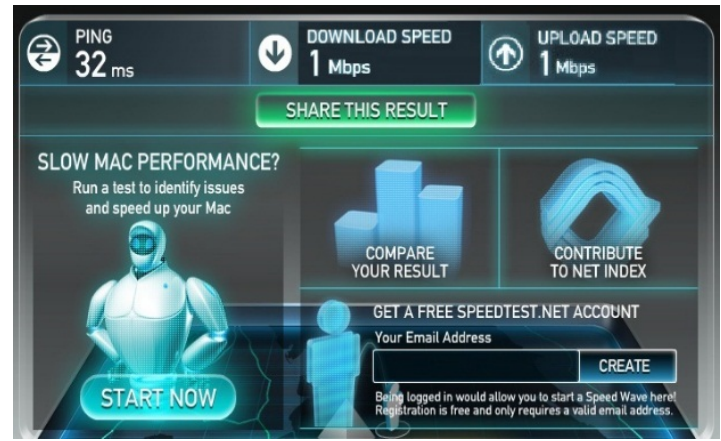

Gambar 7. Status limit 


\subsubsection{Pemonitoringan Bandwidth Mikrotik dengan Web}

Pada gambar 8 dan 9 menunjukkan grafik penggunaan bandwidth yang digunakan semua perangkat yang terhubung ke Mikrotik yang dihitung adalah penggunaan harian yang di-update setiap lima menit, setiap minggu yang di-update setiap tiga puluh menit, setiap bulan yang di-update setiap dua jam, setiap tahun yang di-update setiap satu hari dan pemberitahuan maksimal batasan serta last update web.

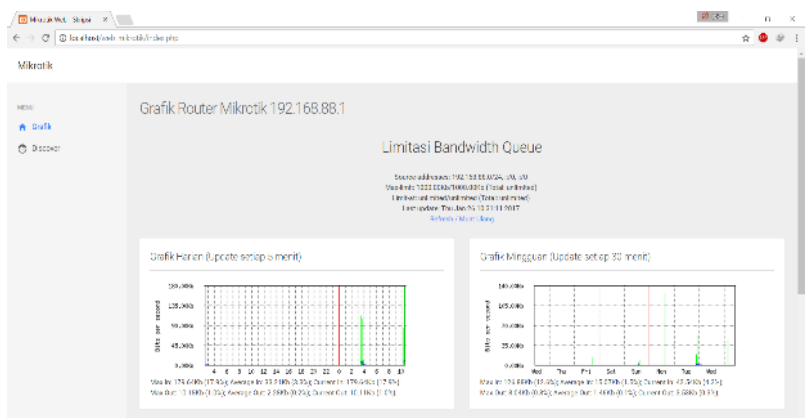

Gambar 8. Grafik pengguanan bandwidth Mikrotik harian dan mingguan

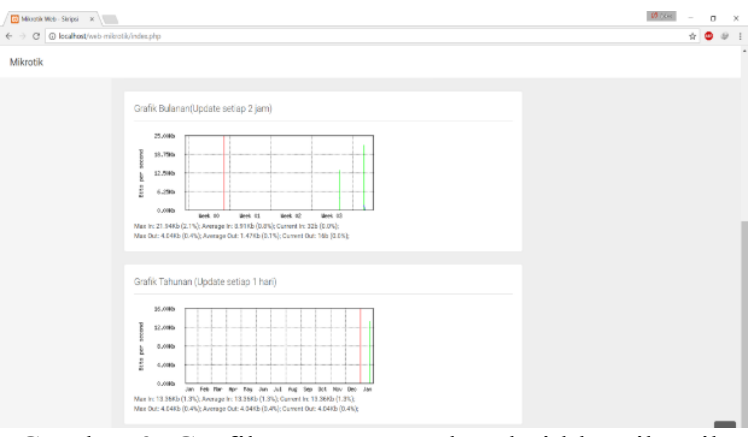

Gambar 9. Grafik pengguanan bandwidth Mikrotik bulanan dan tahunan

\subsection{Pembahasan}

Pada pengujian terhadap sistem, didapatkan hasil sistem monitoring ini mampu memonitor perangkat yang up dan down ke email, membatasi pengguanaan bandwidth serta memonitoring penggunaan bandwidth yang digunakan semua perangkat yang terhubung ke Mikrotik.

Pada skenario pertama, sistem mampu mengirimkan notifikasi ke email saat perangkat up (terhubung) ke router Mikrotik dengan status waktu perangkat tersebut up. Kemudian dilakukan percobaan pada skenario kedua dengan mengirimkan notifikasi ke email saat perangkaat down (terputus) ke router Mikrotik dengan status waktu perangkat tersebut down. Kemudian pada tahap ketiga dilakukan pembatasan pengguanaan bandwidth pada Mikrotik dengan limitasi maksimal 1 Mbps. Pada tahap terakhir dilakukan pemantauan grafik penggunaan bandwidth yang digunakan semua perangkat yang terhubung ke Mikrotik yang dihitung pergunaan harian $10 \mathrm{~GB}$ yang di-update setiap lima menit, setiap minggu 70 GB yang diupdate setiap tiga puluh menit, setiap bulan 2 TB yang di-update setiap dua jam, setiap tahun 720 TB yang di-update setiap satu hari dan pemberitahuan max limit serta last update web hari melalui web.

Hasil dari penelitian ini mampu memberi informasi bagaimana semua skenario-skenario notifikasi ke e-mail saat terjadi up dan down perangkat yang terhubung ke Mikrotik dan memonitoring pengguanaan bandwidth dari router Mikrotik, namun pada kenyataannya sistem ini hanya mampu memberi informasi pada keempat skenario tersebut, masih perlu pengembangan sistem kedepannya untuk meningkatkan kinerja sistem monitoring ini. dalam penerapannya sistem ini masih sangat bergantung pada e-mail gmail yang dimiliki oleh administrator sebagai pihak penerima laporan.

\section{Kesimpulan}

Topologi yang cocok pada C.V. teknika bangun wacana adalah pc admin berperan sebagai pc yang memonitor pc client dalam kondisi hidup dan mati. Router Mikrotik berfungsi sebagai penghubung dari pc ke internet service provider dan juga berfungsi sebagai aplikasi untuk memanajemen kapasitas bandwidth.

Sistem The dude berbasis Mikrotik untuk deteksi status device up dan down.

Sistem yang telah dibuat mampu memberi notifikasi status up dan down ke pada admin 
melalui email yang saat diuji menggunakan dua skenario berbeda.

\section{Saran}

Pada implementasi kali ini, topologi yang digunakan sangat sederhana. Kelak dapat diimplementasikan di topologi yang lebih besar. Dalam penerapannya sistem ini masih sangat bergantung pada e-mail gmail yang dimiliki oleh admin sebagai pihak penerima laporan.

\section{Daftar Pustaka}

[1] Citraweb Nusa Infomedia., 2015. "Mengenal Mikrotik dengan PC Router". Diakses dari http://www.mikrotik.co.id/artikel_lihat.php?id $=113$, pada Juli 2017 .

[2] Widiyasono, 2009. "Pengertian Mikrotik". diakses dari http://www.mandalamaya.com/pengertianMikrotik/ pada Oktober 2016.

[3] A, Zainal, Y. Rachmawati, dan J. Triyono. "Analisis Perbandingan Kinerja Metode Routing Static pada PC Router Ubuntu dan Mikrotik Router (Studi Kasus pada Laboratorium Komputer \& Jaringan, Institut Sains \& Teknologi AKPRIND Yogyakarta)." Jurnal Jarkom 5.2. pp 146-156. 2017.

[4] A. Khozaimi. "Implementasi Jaringan Point To Multipoint Dengan Mikrotik Rb 433 Pada Jaringan Internet Asrama Mahasiswa Universitas Trunojoyo Madura" Jurnal NERO. Vol 3, No 1. Pp.53-60. 2017.

[5] Citraweb Nusa Infomedia., 2005. Monitoring dengan aplikasi The dude Diakses dari http://Mikrotik.co.id/artikel_lihat.php?id=172 pada Agustus 2017.

[6] R. Rinaldo. "Implementasi Sistem Monitoring Jaringan Menggunakan Mikrotik Router OS di Universitas Islam Batik Surakarta". Jurnal Emitor Vol.16 No. 02. pp.5-12. 2016.

[7] Agustina, R., Yusuf, M.Z., Purnama, I., \& Anwar, M.N. "Monitoring Jaringan Menggunakan Mikrotik OS dan The Dude". Jurnal Teknologi, Universitas Kanjuruhan Malang. Vol.6. No.2. pp.124-130. 2013 